
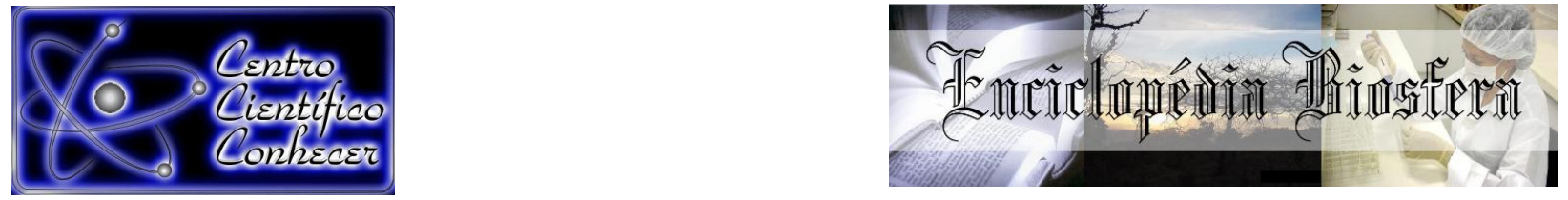

\title{
ESTIMATIVA DA VIABILIDADE POLÍNICA E POLINIZAÇÃO CONTROLADA DE VARIEDADES TRADICIONAIS DE Cucurbita moschata Duchesne
}

\author{
Luziane de Abreu Nachbar ${ }^{1}$; Sérgio Alessandro Machado Souza² \\ ${ }^{1}$ Bióloga, Mestre do Programa de Pós Graduação em Biodiversidade e \\ Agroecossistemas Amazônicos da Universidade do Estado de Mato Grosso - \\ UNEMAT, Alta Floresta, MT, Brasil. *lanachbar@hotmail.com \\ ${ }^{2}$ Professor Doutor da Universidade do Estado do Mato Grosso - UNEMAT, Campus \\ de Alta Floresta, MT, Brasil.
}

Recebido em: 06/04/2018 - Aprovado em: 10/06/2018 - Publicado em: 20/06/2018 DOI: 10.18677/EnciBio_2018A44

\begin{abstract}
RESUMO
Estudos de viabilidade polínica geram informações a respeito do sucesso da fertilização dos grãos de pólen, bem como a forma da biologia reprodutiva das espécies. A viabilidade e a quantidade de grãos de polens depositados sobre o estigma influenciam o sucesso da frutificação, podem gerar impactos econômicos na produtividade de espécies como as abóboras. Este estudo objetiva estimar a viabilidade polínica e o sucesso da polinização controlada de doze acessos de abóboras tradicionais da espécie Cucurbita moschata Duch. cultivadas na região norte do Estado de Mato Grosso. Um dia anterior à antese, botões florais foram coletados e conservados para posterior análise. A estimativa da viabilidade polínica foi realizada com teste colorimétrico com o corante reativo Alexander. As anteras de oito flores por acesso foram seccionadas transversalmente e maceradas. Por lâmina foram contabilizados 250 grãos de pólen, perfazendo um total de 2000 polens por acesso, observados em microscópico ótico na objetiva 40 x. Realizou-se a polinização controlada e evitou-se o cruzamento entre as variedades de $C$. moschata. Flores femininas foram polinizadas manualmente e utilizaram-se polens de uma flor masculina para obtenção de frutos em um único ciclo de produção. Os dados de viabilidade, flores polinizadas e taxa de frutificação foram submetidos à análise descritiva, obtendo a média, intervalo de confiança e desvio padrão. A média de viabilidade foi de $89,83 \%$, sendo o acesso UNEMAT 023 com menor valor $79,4 \%$ e o UNEMAT $016 \mathrm{com}$ maior valor de 97,6\%. Os acessos UNEMAT 015, 018 E 021 apresentaram maiores taxas de frutificação e podem ser indicadas para futuros programas de melhoramento genético da cultura.
\end{abstract}

PALAVRAS-CHAVE: abóboras, grãos de pólen, Recursos genéticos. 


\title{
ESTIMATION OF POLYNICAL VIABILITY AND CONTROLLED POLLINATION OF TRADITIONAL VARIETIES OF Cucurbita moschata Duchesne
}

\begin{abstract}
Pollen viability studies generate information about the success of pollen grains fertilization, as well as the form of the species' reproductive biology. The viability and the quantity of pollen grains deposited on the stigma influences the fruiting success, can generate economic impacts on the productivity of species such as pumpkins. This study aims to estimate the pollen viability and the success of controlled pollination of twelve accessions of traditional pumpkins of the species Cucurbita moschata Duch. cultivated in the northern region of the State of Mato Grosso. One day before the anthesis, floral buds were collected and retained for later analysis. The pollen viability assay was performed with colorimetric test with the Alexander reactive dye. The anthers of eight flowers per access were sectioned transversely and macerated. Twenty-five pollen grains were counted per slide, accounting for a total of 2000 pollen per access, observed in optical microscopy on the $40 \mathrm{x}$ objective. Controlled pollination was carried out and cross-breeding between C. moschata varieties was avoided. Female flowers were manually pollinated and pollen from a male flower was used to obtain fruits in a single production cycle. The viability data, pollinated flowers and fruiting rate were submitted to descriptive analysis, obtaining the mean, confidence interval and standard deviation. The average viability was $89.83 \%$, with UNEMAT 023 access having a lower value of $79.4 \%$ and UNEMAT 016 with a higher value of $97.6 \%$. UNEMAT accessions 015,018 and 021 presented higher fruiting rates and may be indicated for future crop breeding programs.
\end{abstract}

KEYWORDS: Genetic resources, pollen grains, pumpkins.

\section{INTRODUÇÃO}

A abóbora pertence ao gênero Cucurbita e a família Cucurbitaceae possui ampla importância econômica, alimentar e social (SOUZA et al., 2014). Originária das Américas esta espécie tem uma expressiva participação na alimentação humana sendo utilizada na produção de pratos salgados e elaboração de doces em pasta ou calda. Além de o valor alimentar, o cultivo de abóbora promove a geração de empregos diretos e indiretos demandando uma grande quantidade de mão-deobra do cultivo até a comercialização (RESENDE et al., 2013).

As abóboras têm potencial de cultivo entre as culturas de ciclo curto, especialmente nas condições ambientais da região norte do Estado de Mato Grosso, é uma importante alternativa para a agricultura familiar. A espécie C. moschata destaca-se entre as hortaliças convencionais mais cultivadas na região de Alta Floresta /MT (NESPOLI et al., 2015).

Em relação à biologia floral a espécie Cucurbita moschata Duch. apresenta flores monóicas de tamanho relativamente grande, sua coloração varia de amarela a amarela-alaranjada e são plantas de fecundação cruzada - alógamas (ROMANO et al, 2008). A flor masculina produz uma grande quantidade de pólen em suas três anteras soldadas, este pólen apresenta uma textura pegajosa sendo facilmente transportado por insetos polinizadores até a flor feminina que apresenta um ovário bem aparente (RECH et al., 2014).

A frutificação ocorre quando o estigma da flor recebe o grão de pólen. A polinização controlada em flores de abóboras oferece maior eficiência para a fecundação do óvulo, pois a quantidade de grãos de polens viáveis compete pela 
fecundação do óvulo e promove um aumento no número de sementes e na taxa de frutificação (NASCIMENTO et al., 2011).

Estimar a viabilidade do grão de pólen é uma etapa decisiva quando se refere à fertilização da planta, pois ela é um pré-requisito para que o pólen possa germinar (ARENAS-DE-SOUZA et al., 2014). A eficácia desses cruzamentos depende diretamente da viabilidade dos grãos de polens e da receptividade estigmática (LIMA et al., 2016; SOARES et al., 2016). O presente trabalho teve o objetivo de estimar a viabilidade polínica via corante de Alexander e o sucesso da polinização controlada de 12 acessos de abóboras tradicionais da espécie $C$. moschata.

\section{MATERIAL E MÉTODOS}

O experimento foi instalado e conduzido no município de Paranaíta, estado de Mato Grosso (Figura 1). A localização geográfica está definida pelas coordenadas $09^{\circ} 39^{\prime} 20^{\prime \prime} \mathrm{S}$ de latitude, e longitude de $56^{\circ} 28^{\prime} 36^{\prime \prime} \mathrm{W}$, a uma altitude de 249 metros. O índice pluviométrico é de aproximadamente $2.750 \mathrm{~mm}$ e temperatura média anual de $27,6^{\circ} \mathrm{C}$ (IBGE, 2017). O clima é do tipo Am, segundo a classificação de Köppen, ou seja, tropical chuvoso com elevada pluviosidade no verão e um inverno seco, com predomínio de altas temperaturas (ALVARES et al., 2014).

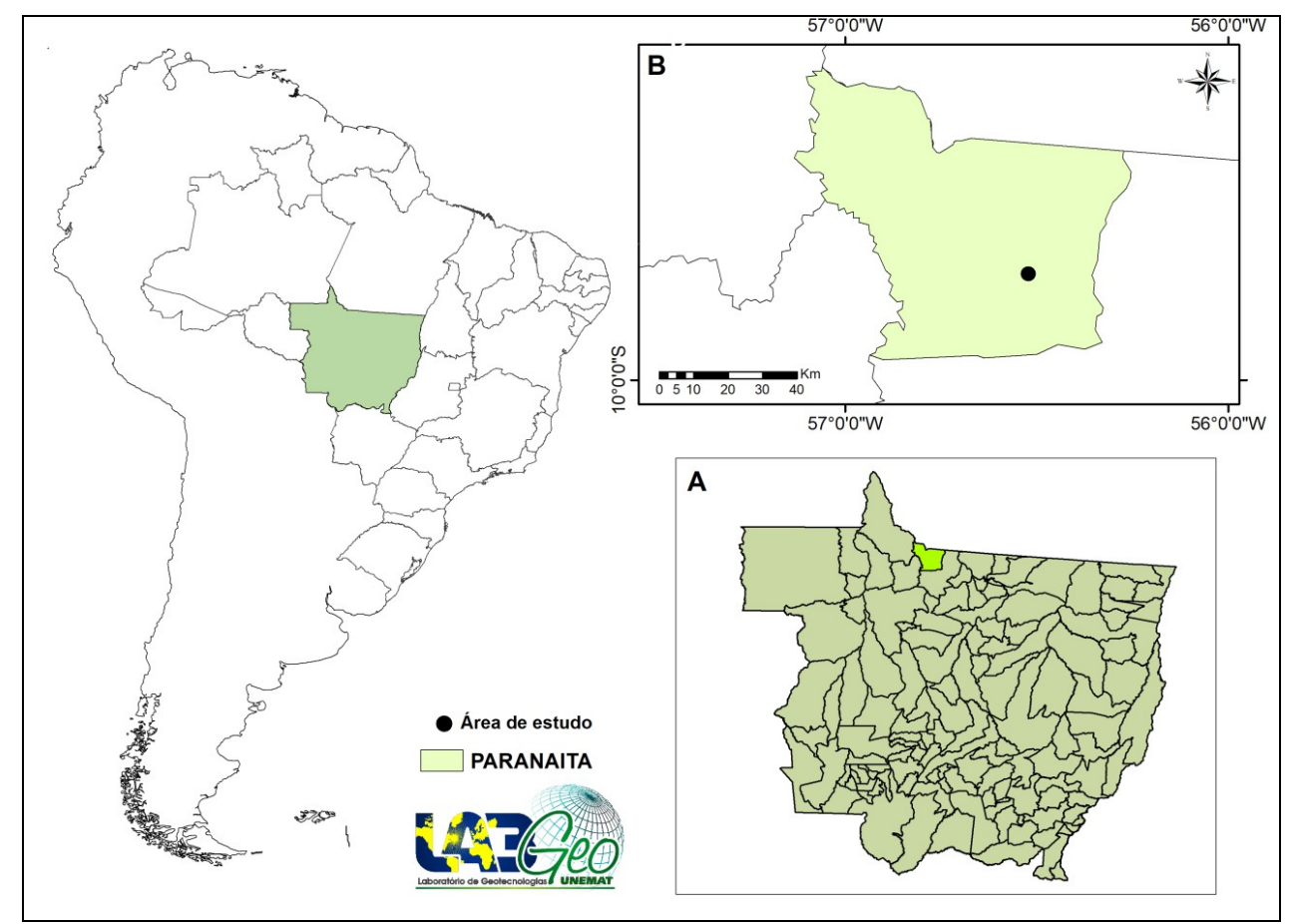

FIGURA 1. Localização do estado de Mato Grosso no Brasil; (A) Localização do Município de Paranaíta no estado de Mato Grosso; (B) Localização da área do experimento no município de Paranaíta - MT.

Fonte: Laboratório de Geotecnologias UNEMAT.

Sementes coletadas nos municípios de Paranaíta, Carlinda, Alta Floresta e Terra Nova do Norte foram semeadas em outubro de 2016, ocorrendo um ciclo de produção (Quadro 1). Os tratos culturais e fitossanitários necessários à cultura foram realizados de acordo com a recomendação técnica (FILGUEIRA, 2008).

QUADRO 1. Descrição dos 12 acessos tradicionais de C. moschata Duch. 


\begin{tabular}{cc}
\hline Acesso & Local de coleta \\
\hline UNEMAT 015 & Alta Floresta \\
UNEMAT 016 & Paranaíta \\
UNEMAT 017 & Paranaíta \\
UNEMAT 018 & Paranaíta \\
UNEMAT 019 & Paranaíta \\
UNEMAT 020 & Paranaíta \\
UNEMAT 021 & Paranaíta \\
UNEMAT 022 & Paranaíta \\
UNEMAT 023 & Terra Nova do Norte \\
UNEMAT 024 & Terra Nova do Norte \\
UNEMAT 025 & Carlinda \\
UNEMAT 026 & Paranaíta \\
\hline
\end{tabular}

Fonte: Própria

Ao iniciar a plena floração, para estimar a viabilidade polínica, botões florais masculinos foram coletados um dia antes da antese e fixados em solução de etanolácido acético (proporção de três partes de álcool absoluto e uma parte de ácido acético glacial $(\mathrm{CH} 3 \mathrm{COOH}))$ por 24 horas, posteriormente transferidos para solução de álcool $70 \%$ e conservados em geladeira. Foi testado o corante reativo de Alexander (ALEXANDER, 1969) onde os grãos de pólen inviáveis apresentam coloração esverdeada e os viáveis ficam da cor púrpura ou vermelha no protoplasto.

Oito lâminas foram preparadas para cada acesso de abóbora estudada. No preparo das lâminas as anteras foram seccionadas na transversal com auxílio de um bisturi sendo posteriormente maceradas para facilitar a liberação do pólen sobre o corante utilizado. Após a retirada manual das impurezas com auxílio de uma pinça, a lâmina foi coberta com uma lamínula e observada ao microscópio óptico a uma magnitude de 400x. Contaram-se 250 grãos de pólen em cada lâmina, perfazendo um total de 2.000 grãos de pólen/acesso avaliado.

Polinizações controladas para evitar o cruzamento entre os acessos cultivados no experimento foram realizadas paralelamente. Diariamente ao entardecer (17h), a porção superior das pétalas dos botões florais femininos e masculinos em pré-antese era levemente amarrada com um barbante e no dia seguinte entre as $6 \mathrm{~h}$ e $11 \mathrm{~h}$, retirou-se a proteção dos botões florais, um botão masculino foi desprendido da planta e retirado suas pétalas, sendo a antera suavemente passada sobre o estigma da flor feminina, assim seus polens aderiam a esta estrutura. Para evitar contaminações de polens de outras flores e entrada de insetos usou-se um saco de papel por três dias para proteger o botão polinizado e uma etiqueta com informações sobre a identificação do acesso e a data da polinização foi anexada no botão. O número de polinizações e os frutos maduros resultantes permitiram avaliar a taxa de frutificação.

A porcentagem de viabilidade polínica foi feita após a contagem do pólen. $\mathrm{O}$ número de flores polinizadas, taxa de frutificação e dados da viabilidade polínica foram submetidos à estatística descritiva, o aplicativo computacional estatístico GENES (CRUZ, 2013) auxiliou na obtenção da média, desvio padrão e intervalo de confiança.

\section{RESULTADOS E DISCUSSÃO}


A espécie C. moschata Duch. apresentou alta taxa de pólen viável (Figura $2 \mathrm{~A}$ ), o corante reativo de Alexander indicou mais de $89 \%$. Este corante permite a visualização do protoplasma na cor púrpura ou vermelha, os grãos inviáveis (Figura 2B) que não apresentam protoplasma e parede celular integra apresenta tonalidade esverdeada (ALEXANDER, 1969), o corante Alexander comparado a outros corantes utilizados para a determinação da viabilidade polínica permite a coloração dos grãos de polens inviáveis evitando equívocos na sua avaliação (SANTOS et al., 2015).

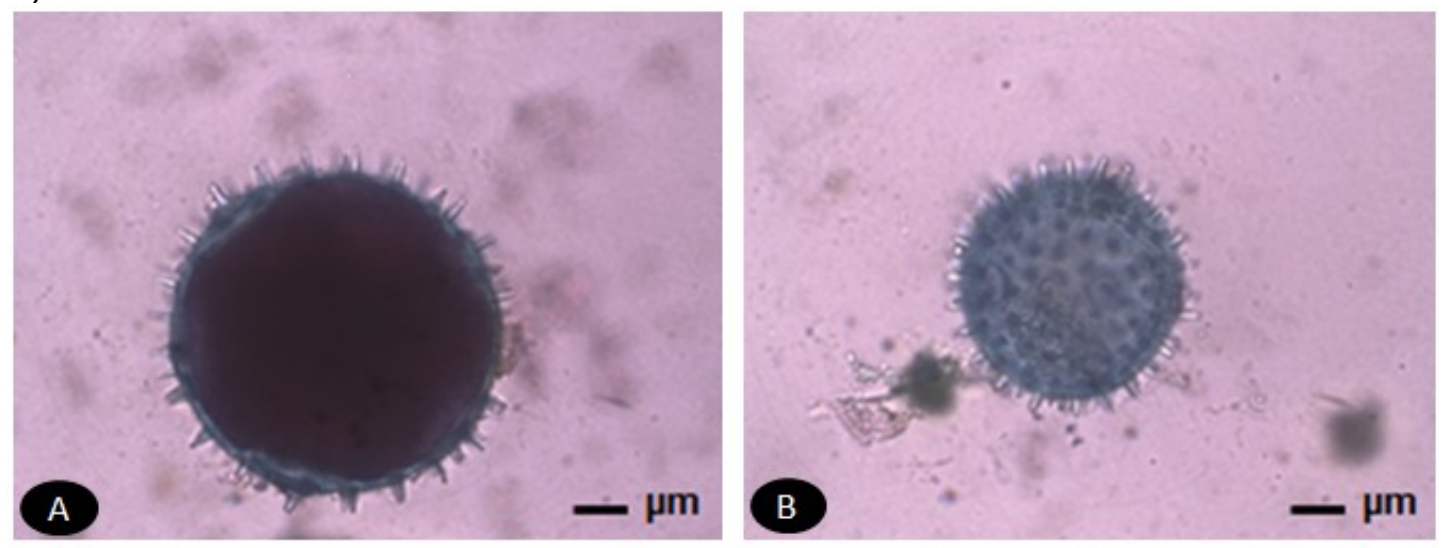

FIGURA 2. Grão de pólen de C. moschata corados com reativo de Alexander; A) viável; B) inviável. Barra $=20 \mu \mathrm{m}$.

Todos os acessos estudados apresentaram médias de viabilidade polínica superiores a $79 \%$, o acesso UNEMAT 023 evidenciou os menores valores de polens viáveis $(79,40 \%)$, com limite inferior de $61,97 \%$ e limite superior de $94,34 \%$ e o acesso UNEMAT 016 com maiores valores de grãos de polens viáveis $(97,60 \%)$, com o limite inferior de 95,46\% e limite superior de 99,43\% (Tabela 1).

TABELA 1. Resultados do Intervalo de confiança (I.C. 95\%), médias, desvio padrão (DP) e Coeficiente de variação (C.V.) da viabilidade polínica dos acessos de abóboras tradicionais estudadas.

\begin{tabular}{|c|c|c|c|c|}
\hline \multicolumn{5}{|c|}{ I. C. $95 \%$} \\
\hline Acesso & LI & LS & Média & DP \\
\hline UNEMAT 015 & 78,48 & 96,62 & 88,25 & 10,62 \\
\hline UNEMAT 016 & 95,46 & 99,43 & 97,60 & 2,32 \\
\hline UNEMAT 017 & 54,35 & 104,96 & 81,60 & 29,63 \\
\hline UNEMAT 018 & 74,96 & 86,54 & 81,20 & 6,78 \\
\hline UNEMAT 019 & 88,05 & 100,67 & 94,85 & 7,38 \\
\hline UNEMAT 020 & 92,99 & 98,11 & 95,75 & 2,99 \\
\hline UNEMAT 021 & 77,98 & 95,65 & 87,50 & 10,34 \\
\hline UNEMAT 022 & 95,40 & 98,46 & 97,05 & 1,78 \\
\hline UNEMAT 023 & 61,97 & 94,34 & 79,40 & 18,95 \\
\hline UNEMAT 024 & 73,34 & 86,45 & 80,40 & 7,67 \\
\hline UNEMAT 025 & 96,23 & 97,65 & 97,00 & 0,82 \\
\hline UNEMAT 026 & 96,52 & 98,24 & 97,45 & 1,00 \\
\hline
\end{tabular}

${ }^{1} \mathrm{LI}=$ limite inferior $\mathrm{e}^{2} \mathrm{LS}=$ limite superior. 
A viabilidade polínica é considerada baixa quando a média atinge até $30 \%$ e alta quando se obtêm médias acima de $70 \%$, quanto maior a média da viabilidade polínica maior a possibilidade de fertilização (SOUZA et al., 2002). As variedades de C. moschata avaliadas apresentaram média geral de $89,83 \%$ semelhante aos resultados encontrados por Nicodemo et al. (2007) com a espécie C. maxima, onde a viabilidade dos grãos de pólen foi de aproximadamente $91 \%$ e Nepi e Pacini (1993) obtiveram viabilidade polínica de 92\% com a espécie C. pepo L.

Ramos et al. (2017), obtiveram resultados com altas médias de viabilidade polínica a partir da aplicação do corante lugol, o qual apresentou média de $82,96 \%$, $85,33 \%$ e $80,83 \%$ em populações 1, 2 e 3 de Momordica charantia L. (Cucurbitaceae) respectivamente. A alta viabilidade polínica pode representar o grau de estabilidade dos genótipos, fornecendo subsídios para auxiliar em programas de melhoramento da espécie (BRANBATTI et al., 2016).

Os acessos UNEMAT 016, 017 e 019 apresentaram menores taxas de frutificação com médias de 45,09\%, 38,70\% e 41,50\% e as médias de viabilidade polínica de $97,60 \%, 91,60 \%$ e $94,85 \%$. E as maiores taxas de frutificação ocorreram entre os acessos UNEMAT 021, 018 e 015 com médias de taxas de frutificação de $68,29 \%, 62,50 \%$ e $62,16 \%$ e as médias de viabilidade polínica de $87,5 \%, 81,20 \%$ e $88,25 \%$ respectivamente (Tabela 2 ).

TABELA 2. Resultados das médias de viabilidade polínica (\%) e taxa de frutificação (\%) dos acessos de abóboras estudadas.

\begin{tabular}{ccc}
\hline Acessos & Viabilidade (\%) & Taxa frutificação (\%) \\
\hline UNEMAT 015 & 88,25 & 62,16 \\
UNEMAT 016 & 97,60 & 45,09 \\
UNEMAT 017 & 91,60 & 38,70 \\
UNEMAT 018 & 81,20 & 62,50 \\
UNEMAT 019 & 94,85 & 41,50 \\
UNEMAT 020 & 95,75 & 47,05 \\
UNEMAT 021 & 87,50 & 68,29 \\
UNEMAT 022 & 97,05 & 52,27 \\
UNEMAT 023 & 79,40 & 56,36 \\
UNEMAT 024 & 80,40 & 59,01 \\
UNEMAT 025 & 97,00 & 55,93 \\
UNEMAT 026 & 97,45 & 47,61 \\
\hline Média & 89,83 & 53,03 \\
\hline
\end{tabular}

Fonte: autores

Em estudos com dois híbridos da espécie C. pepo em diferentes coberturas Olinik et al. (2011) obtiveram uma taxa de frutificação de $25,13 \%$ independente do tratamento utilizado, resultado bem inferior ao encontrado neste estudo. A variação da taxa de frutificação dos acessos de abóboras estudados oscilou entre $38,70 \%$ (UNEMAT 017) a 68,24\% (UNEMAT 021), evidenciando que as variedades se comportam de forma diferenciada nas condições ambientais em que foram dispostas. A variação de temperatura e pluviosidade ocorrida no campo experimental podem interferir no processo de fertilização e pegamento dos frutos (Figura 3). 


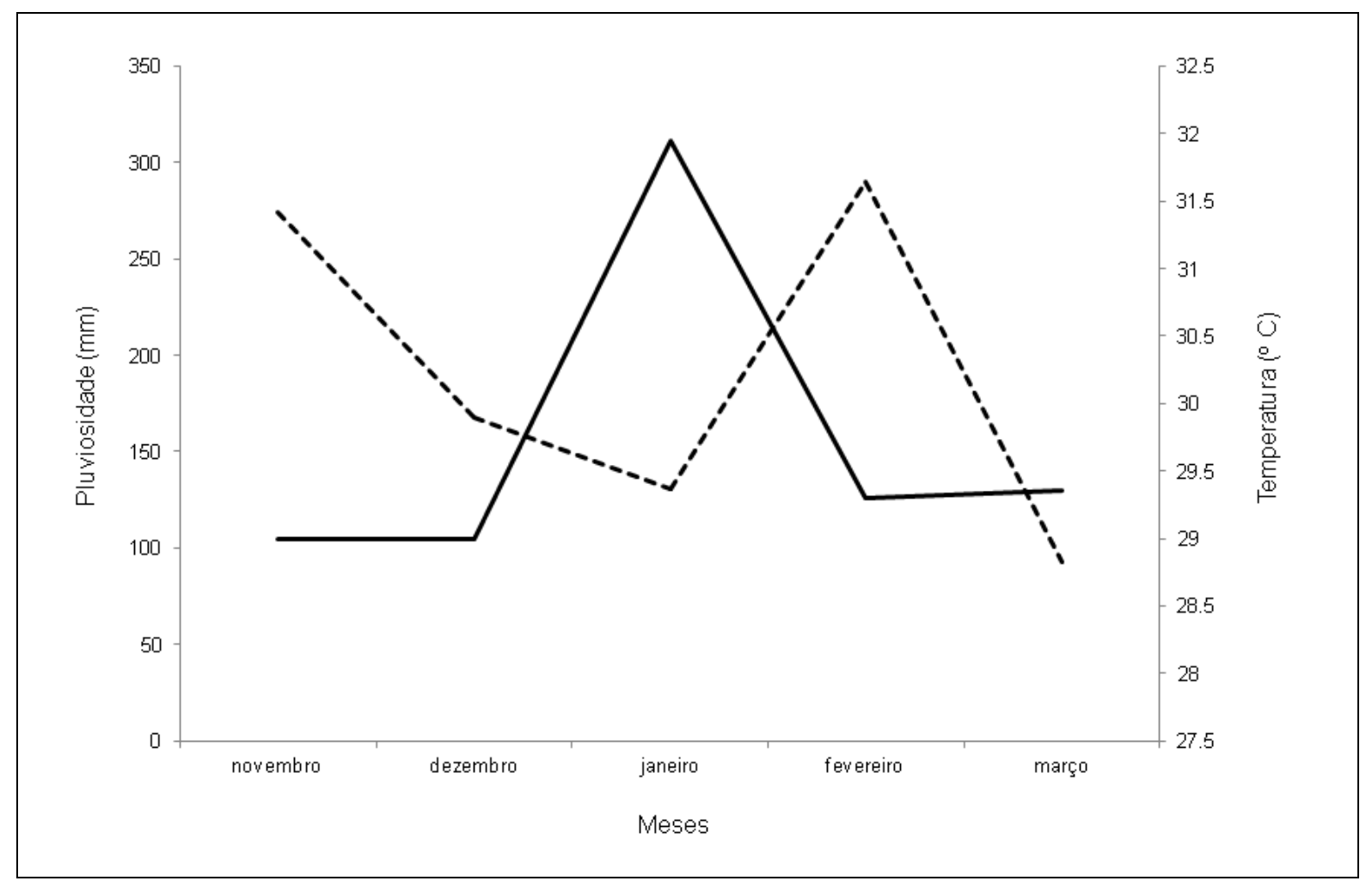

FIGURA 3. Temperatura média $\left({ }^{\circ} \mathrm{C}\right)(-)$ e pluviosidade $(\mathrm{mm})(----)$ para o período de novembro de 2016 a março de 2017, para o município de ParanaítaMT.

Fonte: Autores

Segundo Olinik et al. (2011) as condições climáticas do local de experimentação influenciam intensamente na taxa de pegamento de frutos em abóboras. De acordo com Filgueira (2008) temperaturas médias mínimas de $18^{\circ} \mathrm{C} \mathrm{e}$ máximas de $25^{\circ} \mathrm{C}$ são favoráveis para a polinização e desenvolvimento de frutos em abobreiras. Temperaturas elevadas podem interferir e causar danos no estigma da flor e na germinação do grão de pólen, reduzindo a taxa de frutificação (ZANANDREAL et al., 2011).

As médias de temperaturas na área experimental no período em que ocorreram as polinizações controladas foram de $29^{\circ} \mathrm{C}$ a $32^{\circ} \mathrm{C}$, período de novembro de 2016 a março de 2017. Estas médias de temperaturas podem interferir no sucesso das polinizações e no desenvolvimento inicial dos frutos dos acessos avaliados, pois segundo Giorno et al. (2013) temperaturas elevadas podem interferir negativamente nos processos de liberação do pólen, número de grãos de polens retidos no estigma da flor, germinação do pólen, crescimento do tubo polínico, viabilidade do óvulo, no crescimento do endosperma e do embrião, sendo alguns estágios mais sensíveis do que outros, essa sensibilidade dos órgãos reprodutores masculinos tem sido observada após exposições constante à temperatura de $32^{\circ} \mathrm{C}$.

\section{CONCLUSÕES}

Os acessos UNEMAT 015, 018 e 021 destacaram-se por apresentarem as maiores taxas de frutificação e alta viabilidade polínica nas condições de polinização controlada. Estes acessos podem ser indicados para subsidiar futuros programas de melhoramento genético e para fins de conservação dos recursos genéticos. 


\section{AGRADECIMENTOS}

À Secretaria de Estado de Educação, Esporte e Lazer de Estado de Mato Grosso (SEDUC/MT) e Secretaria de Estado de Ciência e Tecnologia (SECITEC/MT) pela concessão de licença para qualificação profissional para a primeira autora e ao Programa de Pós-Graduação em Biodiversidade e Agroecossistemas Amazônicos, UNEMAT, pela oportunidade de estudo e por ter permitido o desenvolvimento desta pesquisa.

\section{REFERÊNCIAS}

ALEXANDER, M.P. Differential staining of aborted and noaborted pollen. Stain Technology, n.1, v. 44, p. 117-122, 1969. Disponível em: <https://www.tandfonline.com/doi/abs/10.3109/10520296909063335>.

DOI:10.3109/10520296909063335.

ALVARES, C.A.; STAPE, J.L.; SENTELHAS, P.C.; GONÇALVES, J.L.M.; SPAROVEK, G. Koppen's climate classification map for Brazil. Meteorologische Zeitschrift, v. 22, n.6, p. 711-728, 2014. Disponível em: <http://www.lerf.eco.br/img/publicacoes/Alvares_etal_2014.pdf>. DOI 10.1127/09412948/2013/0507.

ARENAS-DE-SOUZA, M.D.; SILVEIRA, G.F.; SILVA, M.S.A.; KARSBURG, I.V. Estimativa da viabilidade polínica em indivíduos de Tabebuia impetiginosa e Tabebuia chrysotricha (Mart. Ex. DC.) Standl (Bignonisceae) através de métodos de citoquímicos. Enciclopédia Biosfera, Centro Científico Conhecer. V. 10, n.18, p.3864, $2014 . \quad$ Disponível em: <www.conhecer.org.br/enciclop/2014a/MULTIDISCIPLINAR/estimativa.pdf>.

BRANBATTI, a., BRAMMER, S.P.; WIETHÖLTER, P. JUNIOR, A. do N. Estabilidade genética em triticale estimada pela viabilidade polínica. Instituto Biológico, v. 83, p. 01-07, 2016. Disponível em: <http://dx.doi.org/10.1590/1808-1657000802014>. DOI $10.1590 / 18081657000802014$.

CRUZ, C.D. GENES - a software package for analysis in experimental statistic and quantitative genetics. Acta Scientiarum Agronomy. Maringá, v. 35, n. 3, p. 271-276, 2013. Disponível em: <http://www.scielo.br/pdf/asagr/v35n3/v35n3a01.pdf>. DOI 10.4025/actasciagron.v35i3.21251.

FILGUEIRA, F.A.R. Novo manual de oleiricultura: agrotecnologia moderna na produção e comercialização de hortaliças. 3. ed. Viçosa: UFV, 2008. 412 p.

GIORNO, F.; WOLTERS-ARTS, M.; MARIANI, C.; RIEU, I. Ensuring Reproduction at High Temperatures: The Heat Stress Response during Anther and Pollen Development. Plants, v.2, p. 489-506, 2013. Disponível em: <https://www.ncbi.nlm.nih.gov/pmc/articles/PMC4844380/>. 10.3390/plants2030489. 
IBGE. Instituto Brasileiro de Geografia e Estatística - Cidades - Clima. Disponível em: < https://cidades.ibge.gov.br/brasil/mt/panorama>. Acessado em 18 de março de 2017.

LIMA, C. S. M.; RUFATO, A. R.; FACHINELLO, J. C.; ANDRADE, S. B; GAUTÉRIO, G. R. Caracterização dos aspectos florais de cultivares de pereira (Pyrus sp.) e marmeleiro (Cydonia oblonga Mill). Revista Inova Ciência \& Tecnologia, Uberaba, n. 3, p. 20-27, 2016. Disponível em: <http://dx.doi.org/10.1590/S0100$29452004000200005>$. DOI 10.1590/S0100-29452004000200005.

NASCIMENTO, W.M; LIMA, G.P.; CARMONA, R. Influência da quantidade de pólen na produção e qualidade de sementes híbridas de abóbora. Horticultura Brasileira, Brasília, v.29, n.1, p.21-25, 2011. Disponível em: <http://dx.doi.org/10.1590/S010205362011000100004>. DOI 10.1590/S0102-05362011000100004.

NEPI, M.; PACINI, E. First observations on nectaries and nectar of Cucurbita pepo. Plant Biosystem, Reino Unido, v.127, n.6, p.1208-1210, 1993. Disponível em: <https://doi.org/10.1080/11263509309429512>. $10.1080 / 11263509309429512$.

NESPOLI, A. COCHEV, J.S. NEVES, S.M.A.S.; SEABRA JÚNIOR, S. Produção de hortaliças pela agricultura familiar de Alta Floresta, Amazônia Matogrossense. Campo-Território: revista de geografia agrária, Uberlândia, v.10, n. 21, p. 159191, 2015.2 Disponível em: <http://www.seer.ufu.br/index.php/campoterritorio/article/view/28714>.

NICODEMO, D.; COUTO, R.H.N.; MALHEIROS, E.B.; DE JONG, D. Biologia floral em Moranga (Cucubita maxima Duch. var." Exposição"). Acta Scientiarum Agronomy, Maringá, v.29, p.611-616, 2007. Disponível em: <http://dx.doi.org/10.4025/actasciagron.v29i5.735>.

$\mathrm{DOI}$ 10.4025/actasciagron.v29i5.735.

OLINIK, J. R.; OLIVEIRA JÚNIOR, A.; KEPP, M.A.; REGHIN, M.Y. Produtividade de híbridos de abobrinha italiana cultivados sob diferentes coberturas de solo. Horticultura Brasileira, Brasília, v.29, n.1, 2011. Disponível em: <http://dx.doi.org/10.1590/S0102-05362011000100023>. DOI 10.1590/S010205362011000100023.

LABGEO UNEMAT - Laboratório de Geotecnologias Unemat. Disponível em: < http://www2.unemat.br/labgeo>. Acesso em: nov. 2017.

SANTOS, T.A.; TIAGO, P.V.; SCHMITT, K.F.M.; ROSSI, A.A.B. Viabilidade Polínica em Bertholletia excelsa Bonpl. (LECYTHIDACEAE) baseada em diferentes testes colorimétricos. Enciclopédia Biosfera , Goiânia, v. 11, n.22, p.3136-3144, 2015. Disponível em: <https://www.researchgate.net/publication/285548170_Viabilidade polinica em Bertholletia_excelsa_Bonpl_Lecythidacea baseada em diferentes testes colorimetricos>. DOI 10.18677/Eñciclopēdia_Biosfera_2015_030.

SOARES, T. L.; SOUZA, E. H.; COSTA, M. A. P. C.; SILVA, S. O.; SANTOSSEREJO, J. A. Viability of pollen grains of tetraploid banana. Bragantia, Campinas, 
v. 75 , p. 30, 2016. Disponível em: <http://dx.doi.org/10.1590/1678-4499.328>. DOI 10.1590/1678-4499.328.

SOUZA, M.M.; PEREIRA, T.N.S.; MARTINS, E.R. Microsporogênese associada ao tamanho do botão floral e da antera e viabilidade polínica em maracujá amarelo (Passiflora edulis Sims f. flavicarpa Degener). Ciência e Agrotecnologia. Lavras, v. 26, n. 1, p. 1209-1217, 2002. Disponível em: $<$ file:///C:/Users/lanac/AppData/Local/Packages/Microsoft.MicrosoftEdge_8we kyb3d8bbwe/TempState/Downloads/26-6-2002_13.pdf>.

SOUZA, E.G.F.; SANTANA, F.M.S.; MARTINS, D.L.P.; BARROS JÚNIOR, A.P., SILVEIRA, L.M. Produção de mudas de cucurbitáceas utilizando esterco ovino na composição de substratos orgânicos. Revista Agroambiente, Roraima, v. 8, n.2, p. 175-183, 2014. Disponível em: < DOl: http://dx.doi.org/10.18227/19828470ragro.v8i2.1675>. DOI: 10.18227/1982-8470ragro.v8i2.1675.

RAMOS, L.P.N.; ANDRÉ, V.L.S.; MELLO, V.S.; KARSBURG, I.V. Estimativa da viabilidade polínica do melão-de-são-caetano (Momordica charantia L) com diferentes métodos de coloração. Agrarian Academy, Goiânia, v. 4, n.7, p.236-245, 2017. Disponível em: <http://www.conhecer.org.br/Agrarian \%20Academy/2017a/estimativa\%20da\%20viabilidade.pdf>.

10.18677/Agrarian_Academy_2017a23.

RECH, A.R.; AGOSTINI, K.; OLIVEIRA, P.E.; MACHADO, I.C. Biologia da polinização. Rio de Janeiro: Projeto cultural, 2014. 527p.

RESENDE GM; BORGES RME; GONÇALVES NPS. Produtividade da cultura da abóbora em diferentes densidades de plantio no Vale do São Francisco. Horticultura Brasileira, Brasília, v. 31, n.3, p. 504-508, 2013. Disponível em: <http://dx.doi.org/10.1590/S0102-05362013000300027>. DOI 10.1590/S010205362013000300027.

ROMANO, C.M.; STUMPF, E.R.T.; BARBIERI, R.L.; BEVILAQUA, G.A.P.; RODRIGUES, W.F. Polinização Manual em abóboras. Embrapa Clima Temperado, Pelotas, 2008.

ZANANDREAL, I.; RASEIRALL, M.C.B.; SANTOS, J.; SILVA, J.B. Receptividade do estigma e desenvolvimento do tubo polínico em flores de pessegueiro submetidas à temperatura elevada. Ciência Rural, Santa Maria, v. 41, n.12, p. 2066-2972, 2011. Disponível em: <http://dx.doi.org/10.1590/S0103-84782011001200005>. DOI 10.1590/S0103-84782011001200005. 